\title{
A FORMAÇÃO DE UMA BIBLIOTECA DIGITAL, ATRAVÉS DOS SUMÁRIOS CORRENTES DE PERIÓDICOS DA ÁREA EDUCACIONAL : PROCEDIMENTOS, METODOLOGIA E ACESSO ONLINE DE DOCUMENTOS
}

\section{Gildenir Carolino Santos Rosemary Passos}

\begin{abstract}
Resumo
O presente trabalho descreve o resultado de uma experiência realizada na Biblioteca da Faculdade de Educação da UNICAMP com o propósito de disponibilizar via acesso Internet, o seu acervo de periódicos, através dos sumários digitalizados, com o intuito de tornar-se uma obra de referência e uma fonte de indexação de títulos de periódicos nacional ou internacional. Explicita um enfoque para a questão da necessidade de criação de mecanismos nas bibliotecas universitárias que viabilizem o acesso a informações mais atuais (periódicos), objetivando no futuro, a digitalização do texto completo dos artigos de periódicos nacionais, com autorização e/ou convênios com as instituições responsáveis pelos direitos autorais. A partir dos procedimentos adotados para construção dos sumários, observa-se as condições favoráveis à implantação de uma biblioteca eletrônica.
\end{abstract}

\section{Palavras-Chave}

Biblioteca Digital ; Biblioteca eletrônica; Biblioteca universitária; Periódicos online ; Sumários correntes online

\begin{abstract}
The present paper describes the result of an experience accomplished at the Library of the Faculty of Education of UNICAMP with the proposal of turning available through access Internet, its collection of serials, through of the digitalized contents, with the pretense of becoming a reference work and a source of national or international indexation of titles of serials. Explicit a focus for the subject of the need of creation of mechanisms in the university libraries that make possible the access to more current information (serials), objectifying in the future, the digitalization of the full text of the articles of national serials, with authorization and/or agreements with the responsible institutions for the copyrights. Starting from the procedures adopted for construction of the contents, it is observed the favorable conditions to the implantation of an electronic library.
\end{abstract}

\section{Key-words}

Digital library ; Electronic library; University library; Online serials ; Online Currents contents 


\section{INTRODUÇÃO}

O investimento na qualidade dos serviços técnicos e administrativos, têm sido um dos principais objetivos almejados pela administração da Biblioteca da Faculdade de Educação da Universidade Estadual de Campinas - Biblioteca FE/UNICAMP .

Apesar dos problemas comuns, enfrentados por toda administração que pretende se aperfeiçoar e crescer, buscando, mesmo que de forma "atropelada" se destacar no mercado da informação, seja ela digital, virtual, em papel, podemos afirmar com certeza que estamos nos desenvolvendo, com resultados favoráveis, que funcionam como dispositivos estimuladores para atingirmos o nosso propósito de desenvolver um bom trabalho em nossa comunidade universitária e principalmente, levar ao conhecimento de outras instituições um pouco das nossas realizações, e da nossa vontade de garantirmos nosso espaço no " momento globalizado".

O princípio de nosso trabalho é centrado em nossos usuários, eles determinam as ações que devemos realizar. "A diferença fundamental está no nível de exigência cada vez maior desses usuários, implicando na adoção de modernos processos de gestão, nos quais a qualidade é um fator essencial para o sucesso de qualquer atividade." (LUZ, 1999).

Nossos esforços sempre foram voltados para o cumprimento do papel principal dos profissionais bibliotecários, que é possibilitar o acesso a informação, de forma rápida e eficiente.

Dispomos à nosso favor, de uma estrutura organizada pelo Sistemas de Bibliotecas da UNICAMP - SBU, que viabiliza o contato com diversos Sistemas Informacionais, Cursos de Aperfeiçoamentos, o que nos mantêm atualizados e em condições de buscar algumas inovações, que possam ser aplicadas em nossa biblioteca, favorecendo à clientela, mas de acordo com nossas possibilidades, visto que somos uma biblioteca média com um acervo de 22.320 volumes e 1.570 usuários, com um número reduzido de funcionários ( 2 bibliotecários e 5 auxiliares).

Contamos também com o apoio dos professores na construção e aplicação dos projetos desenvolvidos pela Biblioteca FE/UNICAMP, e de suas colaborações com sugestões e críticas, que resultam em grande contribuição na elaboração e desenvolvimento das diversas etapas que envolvem cada projeto.

Não poderíamos deixar de mencionar o apoio da FAPESP - Fundação de Amparo à Pesquisa do Estado de São Paulo, que analisa cada projeto, possibilitando sua execução e concretização, viabilizados através do fornecimento de recursos financeiros.

Atualmente, nos dedicamos ao Setor de Periódicos de nossa biblioteca. Estabelecemos como princípio na nossa metodologia de serviços, centrar os esforços do maior número de funcionários, por um determinado período no setor que necessite de um pouco mais de agilidade na fruição de sua rotina de serviços.

O Setor de Periódicos da Biblioteca FE/UNICAMP, tem atingido satisfatoriamente todas as expectativas quanto sua rotina diária (COMUT, Preparo Técnico de Periódicos, Elaboração de Sumários, etc.), o que nos incentiva à acrescentar novos serviços ao Setor, investir na capacitação dos auxiliares de biblioteca e principalmente regularizar o serviço de indexação dos principais periódicos nacionais em Educação (Edubase), consultados por nossos usuários na Biblioteca da FE/UNICAMP. (SANTOS e PASSOS, 1997). 
Para tanto, organizamos a equipe dos funcionários no intuito de que todos possam se interagir, conhecendo o novo serviço, colaborando na sua implementação, até o momento em que este venha a fazer parte de nossa rotina de trabalho normal. Estamos nos referindo a implementação dos Sumários de Periódicos Online da Biblioteca FE/UNICAMP, e de como, através da digitalização dos índices dos periódicos, e dos procedimentos adotados para a realização deste serviço, surgem possibilidades que nos levam a visualizar algo maior, como a criação de uma biblioteca digital/eletrônica na Área de Educação em âmbito nacional.

É nesse contexto de colaboração entre alunos, professores, bibliotecários e auxiliares de biblioteca, que descrevemos esta experiência realizada na Biblioteca FE/UNICAMP, e os caminhos que nos foram apresentados no decorrer deste trabalho, caminhos longos, mas que com certeza teremos muito prazer em percorrer.

\section{JUSTIFICATIVA}

Em nosso trabalho diário notamos a necessidade de viabilizar com urgência o acesso as informações mais atuais (periódicos). Acreditamos que este seja um problema que preocupa a grande maioria das Bibliotecas Universitárias, visto que "utilizar periódicos [para busca por assuntol é mais complexo e atordoante do que os [próprios] bibliotecários se importam em admitir. Os passos necessários para o atendimento bem sucedido de uma necessidade de informação podem desanimar qualquer usuário, a não ser os que forem mais decididos. É fundamental o auxílio da referência no caso dos periódicos."(GROGAN, 1995).

O desenvolvimento científico e tecnológico fez com que as publicações periódicas triplicassem o número de informações correntes, aumentando com isso as dificuldades em cercar toda esta documentação, e disponibilizá-la em tempo hábil para que não se tornassem ultrapassadas.

"Todas as pessoas que lidam hoje com o periódico científico no âmbito de uma biblioteca universitária - bibliotecários, pesquisadores e alunos, e a própria direção da Universidade - raramente estão satisfeitas com a situação existente". (MUELLER, 1994)

É interessante salientarmos que o quadro apresentado não é característica exclusiva do século XXI. O empenho na organização, disseminação e acesso rápido aos títulos e artigos de periódicos vêm de 1848, quando um jovem bibliotecário assistente , William Frederick Poole, compilou um índice manuscrito contendo vários títulos de periódicos diferentes numa única sequiência alfabética, criando assim um novo instrumento de controle bibliográfico, poderíamos dizer até, que temos aí o primeiro sumário de periódicos de uma biblioteca.(GROGAN, 1995).

Atualmente alguns projetos nacionais e internacionais, tem disponibilizado o maior número possível de revistas em texto completo.

Como iniciativas de projetos bem sucedidos na área, e que figuram como exemplos a serem seguidos podemos citar :

$>$ SciELO - Scientific Electronic Library Online - é uma biblioteca virtual que abrange uma coleção selecionada de periódicos científicos brasileiros ; é a aplicação de um projeto de pesquisa da Fundação de Amparo à Pesquisa do Estado de São Paulo - FAPESP, em parceria com o Centro Latino-Americano e do Caribe de Informação em Ciências da Saúde - BIREME, que tem por objetivo o desenvolvimento de uma 
metodologia comum para a preparação, armazenamento, disseminação e avaliação da produção científica em formato eletrônico, via Internet com mais de 100 títulos de periódicos nacionais de diversas áreas do conhecimento em formato completo. (SciELO, 1998).

ProBE - Consórcio para o Desenvolvimento de Biblioteca Eletrônica da Publicações Científicas visa disponibilizar o acesso ágil e atualizado às revistas publicadas pela Elsevier para toda a comunidade científica das Universidades Estaduais Paulistas UNICAMP, USP e UNESP; das Universidades Federais no Estado de São Paulo - UNIFESP e UFSCar e da BIREME, via Internet com mais de 606 títulos de periódicos estrangeiros das diversas áreas do conhecimento em formato completo. (ProBE, 1999).

Ressaltamos nesse momento a importância desses projetos e a colaboração que trouxeram ao nosso trabalho de buscas bibliográficas online.

Estatisticamente, podemos constatar que a predominância dos assuntos indexados corresponde a Área de Ciências e Tecnologias, sendo que a Área de Humanas, ocupa um lugar pouco significativo.

Sabemos que a estrutura destes projetos está alicerçada em longos estudos, elaboração de vários pré projetos, para que finalmente se consiga um resultado, como podemos comprovar quando acessamos qualquer uma dessas bases.

"No cenário americano e no europeu, as novas soluções passam todas pela comunicação eletrônica . E esta tendência certamente terá impacto nas bibliotecas

brasileiras. Entre os novos meios que vêm sendo utilizados ou estudados para a divulgação da informação, científica e técnica, as que provavelmente terão maior impacto são os periódicos eletrônicos e os serviços de acesso documento, também estes, muitas vezes eletrônicos (document delivery)." (MUELLER, 1994)

Cremos, porém que, se cada Biblioteca Universitária fizer um pouco da sua parte, poderemos alcançar em números, a desvantagem a que fomos colocados, na questão da recuperação de informações de periódicos por assunto, pois ainda não temos conhecimento da disponibilidade desses recursos na maioria das bibliotecas brasileiras, sabemos que todas estão caminhando para atingir tal intento, portanto todas as contribuições nesse sentido são bem-vindas.

Para o futuro, BROWN (1993) citado por MUELLER (1994) "preconiza um cenário em três fases: primeiro é necessário que as bibliotecas adquiram mais eficiência com os meios eletrônicos do que são capazes agora, embora não se saiba quanto isso vai custar..."

Não podemos vislumbrar que com o investimento em novas tecnologias de informação, teremos a solução de todos os problemas ligados a recuperação dos documentos, para isso devemos considerar as palavras de CUNHA (1994) :

"É preciso manter uma postura crítica em relação a cada tecnologia de informação, não achar que ela é a "resposta" para todos os nosso problemas. É importante que continuemos a avaliar as novas e antigas 
tecnologias, à luz da nossa missão primordial que é a de ajudar nosso cliente a encontrar a informação que precisa, na hora certa e no formato adequado."

\section{OBJETIVOS}

O objetivo geral do presente trabalho, visa atender à demanda de recuperação de informações na área de Educação, encontradas nos periódicos nacionais ou estrangeiros, que compõem o acervo da biblioteca da Faculdade de Educação da UNICAMP.

Dentre os objetivos específicos, no que se refere a digitalização dos sumários de periódicos, podemos salientar alguns itens, que criam subsídios para a necessidade da construção da biblioteca eletrônica. A partir dos procedimentos adotados na realização deste projeto procuramos :

- criar suporte informacional para apoiar as atividades de pesquisa, ensino e extensão;

- estabelecer normas, padrões e formatos para a indexação de materiais bibliográficos, no caso os sumários online dos periódicos que alimentarão a página de acesso;

- disponibilizar as informações existentes na página para o público externo de forma gratuita;

- prover recursos necessários ao bom funcionamento da rede;

- possibilitar a divulgação dos sumários online como fonte de informação e obra de referência na área educacional

- colaborar com o COMUT (Comutação Bibliográfica), criando mais uma fonte de pesquisa de materiais bibliográficos.

\section{METODOLOGIA}

Foram utilizadas diferentes metodologias, adequadas de acordo com a necessidade de cada procedimento para sistematização e elaboração dos sumários online, aplicadas nas 4 etapas essenciais para a criação de um sumário online, descriminadas a seguir.

\section{Formação do sistema em rede}

A implantação dos sumários online de periódicos, foi estruturada à partir da rede local da biblioteca, onde está instalado um servidor com acesso a página da BFE na Internet. Esta rede foi instalada em janeiro de 1998 e atualizada em março de 2000, sendo composta pelos seguintes equipamentos e softwares :

Equipamentos :

- 01 Servidor Pentium II $500 \mathrm{MHz}$ com $9.0 \mathrm{Mb}$ de disco e 256 Memória RAM;

- 01 Microcomputador Pentium MMX $400 \mathrm{~cm}$ 4.3 MB de disco e 32 Memória RAM;

- 01 Scanner HP Jet 6.0;

Software :

- Microsoft Windows NT 4.0 Server;

- FrontPage 2000 (Microsoft);

- Corel Photo-Paint 6.0 (Corel Draw Corp);

\section{Formação do controle dos sumários online}

O controle dos sumários online, exigiu a utilização de uma numeração seqüencial gerada sempre que se salva um documento escaneado.

A numeração é fornecida para a página do sumário principal escaneado, e caso exista mais páginas, o controle passa a ser feito por numeração alfanumérica, como por exemplo : 1345.jpg; 1345 a.jpg; 1345b.jpg, etc.

Para salvamento dos arquivos de documentos escaneados, seleciona-se a opção "salvar em formato JPG" (Joint 
Photographic Experts Group), pois trata-se de um formato de arquivo gráfico utilizado para compactação de arquivos extensos de imagens coloridas, o que permite salvar as imagens gráficas que alguns sumários de periódicos vez ou outra apresentam.

\section{Estrutura e operacionalização da digitalização}

A estrutura dos formatos do processamento da digitalização dos sumários apresenta-se da seguinte forma:

\section{Figura 1 - Esquema de digitalização dos sumários online}

4

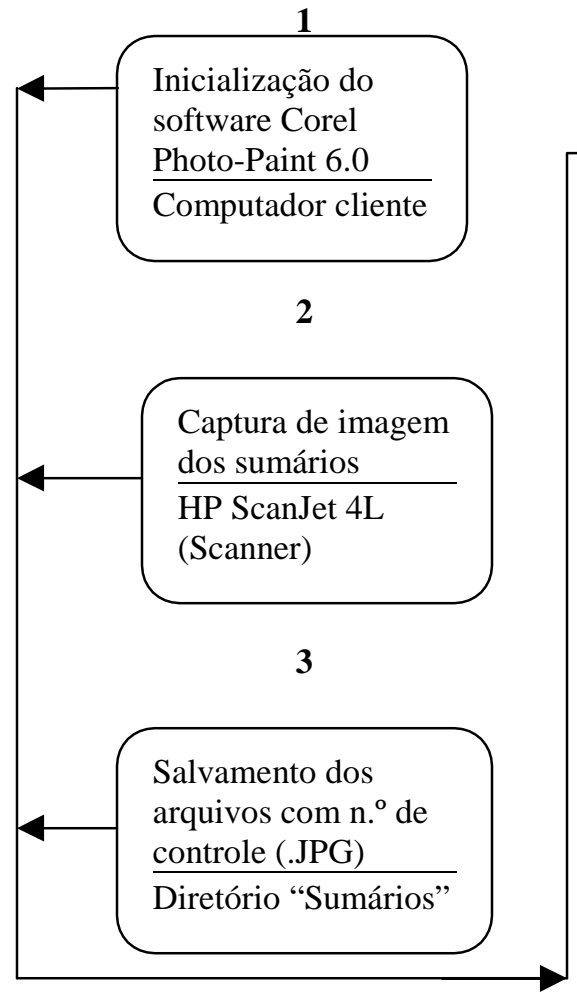

Digitação dos

títulos escaneados

FrontPage 3.0

(HTML)
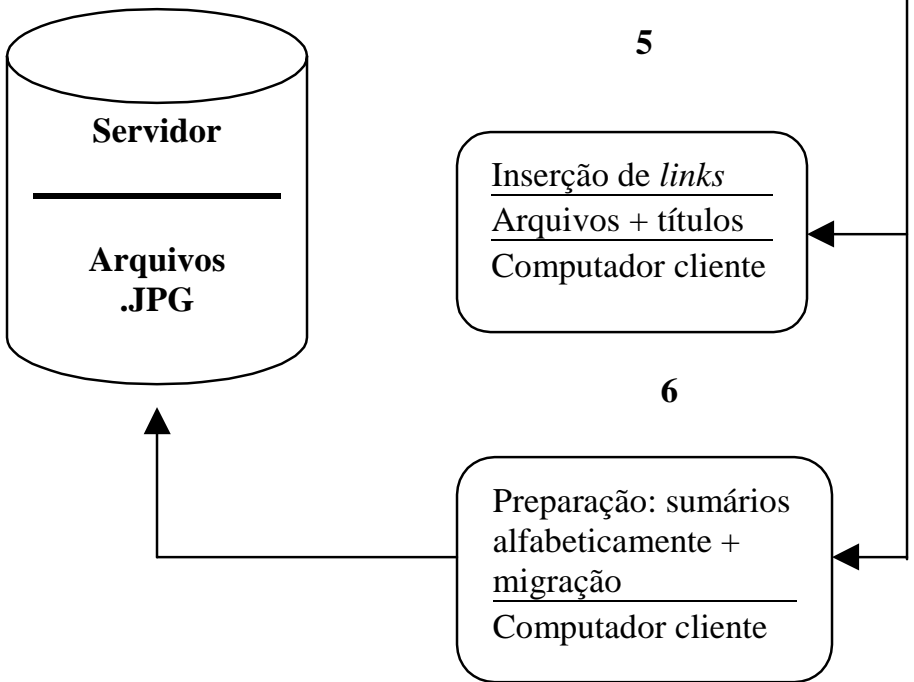

\section{Treinamento do pessoal técnico}

Após a estruturação do serviço de digitalização dos sumários online, houve a necessidade de promoção de treinamentos internos, para obtermos melhor aproveitamento dos recursos bibliográficos disponíveis, e sobretudo qualificar o pessoal técnico, criando condições para que pudessem manusear equipamentos $\mathrm{e}$ softwares de forma correta e eficiente, uma vez que desconheciam as formas de operacionalização desses materiais.
O treinamento foi dado pela Diretoria Técnica aos auxiliares de bibliotecários, que receberam instruções para :

- utilizar o scanner para digitalização dos sumários;

- conhecer e aplicar os programas Corel Photo-Paint e do FrontPage;

- realizar o hipertexto e design das páginas;

- elaborar uma página na Internet. 
Com a finalização dos treinamentos, as funcionárias adquiriram noções de como ocorre o processo de criação de uma página na Internet, bem como puderam compreender a importância do trabalho que realizam nos "bastidores" da biblioteca.

\section{Direitos Autorais}

A preocupação com os direitos autorais (copyright), sempre é um fator que deve ser analisado, quando tratamos de reprodução de documentos. No caso da digitalização de sumários de fascículos de periódicos é permitido, pois a finalidade deste serviço é a divulgação eletrônica dos referidos sumários, o que não compromete sua integridade. Os fins do processo de digitalização justificam seus meios, uma vez que a atividade favorece a pesquisa científica e não almeja fins lucrativos. Caso haja interesse em disponibilizar os artigos em texto completo, a Biblioteca da Faculdade de Educação entrará em contato com os autores e/ou editoras responsáveis pelos direitos autorais solicitando autorização e/ou convênios para efetivação do processo.

\section{VANTAGENS}

Durante a realização deste trabalho, foram detectadas algumas vantagens na implantação dos sumários online da Biblioteca da Faculdade de Educação/UNICAMP, de imediato podemos citar os seguintes tópicos:

- acesso gratuito aos títulos do acervo da biblioteca da Faculdade de Educação da UNICAMP;

- acesso em tempo real;

- disponibilidade dos fascículos online dos sumários, além do mês corrente;

- links com títulos dos periódicos que já possuem os artigos texto completo acessíveis na Internet, o que agiliza ainda mais a busca bibliográfica;

- armazenamento dos sumários em formato de CD-ROM; diminuindo o volume dos sumários em papel;

- a periodicidade mensal dos sumários online, permitiu o registro com ISSN, através do IBICT, tornando-se uma obra de referência e uma fonte de indexação para obras periódicas.

- o sumário online funciona como instrumento de apoio, medializado com interface com o software Ariel ( recém instalado na biblioteca), agilizando ainda mais as solicitações do Serviço de Comutação Bibliográfica.

\section{CONSIDERAÇÕES FINAIS}

A princípio a Biblioteca da Faculdade de Educação/UNICAMP, iniciou seus trabalhos em busca de facilitar o levantamento bibliográfico em periódicos. Uma prática comum utilizada era tirar cópias dos sumários dos periódicos recebidos na biblioteca, encaderná-los de acordo com o mês do recebimento e colocá-los à disposição dos usuários, que ao invés de folhear periódico por periódico, tinham uma forma mais amena de realizar um trabalho praticamente braçal.

A idéia de digitalização para os sumários dos periódicos recebidos pela Biblioteca FE/UNICAMP, surge como uma solução para o armazenamento destas listas, que acabaram se tornando pouco atrativas para manuseio, uma vez que nossos clientes de biblioteca preferem realizar a pesquisa em máquina, ocorrendo desta forma a otimização na realização do preparo técnico de periódicos, o que determina maior agilidade na disponibilização de documentos.

O fato de digitalizarmos apenas os sumários, pode parecer de pouca utilidade, 
mas através do sumários temos uma noção do conteúdo de cada título de periódico, e a partir do momento em que passamos a criar links para as revistas que já possuem o seu conteúdo em texto completo, estamos diminuindo o caminho percorrido ao usuário para a finalização de sua pesquisa. A consulta não se limita apenas ao ambiente de nossa biblioteca, uma vez disponibilizado em rede, o Sumário on-line da Biblioteca da Faculdade de Educação, pode ser acessado por comunidades externas à UNICAMP, sendo que eles terão conhecimento do acervo de periódicos de nossa biblioteca.

Quando iniciamos esse pequeno projeto de digitalização dos sumários, mesmo que de uma forma primária, não tínhamos a noção da importância na realização e divulgação de um trabalho criado apenas para melhorar os processos técnicos de periódicos e tornar-se mais um instrumento no auxílio às pesquisas de nossos usuários.

A partir da disponibilização em rede, recebemos diversos e-mails, solicitando informações sobre os procedimentos adotados , para a realização deste trabalho, e o que é mais interessante, recebemos solicitação de instituições externas, para que o título do periódico produzido por eles, seja escaneado e indexado por nossa biblioteca, uma vez que nos tornamos um fonte de indexação à partir do registro de ISSN junto ao IBICT. 


\section{REFERÊNCIAS BIBLIOGRAFICAS}

ProBE - Programa de Biblioteca Eletrônica. [online]. [citado em: 1999]. [data de acesso: 14/01/2000]. Disponível na URL: Internet : $<$ http://www.unicamp.br/bc/elsevier2.html s.

BROWN, Gary. From past imperfects to future perfects. Serials Librarian, v.23, n.3/4, p.109-121, 1993. Apud MUELLER, Suzana Pinheiro Machado. O periódico científico e as bibliotecas universitárias : velhos problemas, novas soluções. In: SEMINÁRIO NACIONAL DE BIBLIOTECAS UNIVERSITÁRIAS, 8., 1994, Campinas, SP. Anais... Campinas, SP : UNICAMP, 1994. p.80-98.

CUNHA, Murilo Bastos . As tecnologias de informação e a integração das Bibliotecas brasileiras. In: SEMINÁRIO NACIONAL DE BIBLIOTECAS UNIVERSITÁRIAS, 8., 1994, Campinas, SP. Anais... Campinas, SP : UNICAMP, 1994. p.105-120.

GROGAN, Denis. A prática do serviço de referência. Brasília, DF : Briquet de Lemos, 1995.

LUZ, Graça Maria Simões. Apresentação. In: RAMOS, Maria Etelvina Madalozzo (Org.). Tecnologia e novas formas de gestão em bibliotecas universitárias. Ponta Grossa : UEPG, 1999.

MUELLER, Suzana Pinheiro Machado. $\mathrm{O}$ periódico científico e as bibliotecas universitárias : velhos problemas, novas soluções. In: SEMINÁRIO NACIONAL DE BIBLIOTECAS UNIVERSITÁRIAS, 8., 1994, Campinas, SP. Anais... Campinas, SP : UNICAMP, 1994. p.80-98.

SANTOS, Gildenir Carolino, PASSOS, Rosemary. Desenvolvimento de base de dados em Educação "Edubase", gerenciada pelo software Micro CDS/ISIS. In: SEMINÁRIO SOBRE AUTOMAÇÃO EM BIBLIOTECAS E CENTRO DE DOCUMENTAÇÃO, 6., 1997, Águas de Lindóia. Anais... Águas de Lindóia : [s.n.], 1997. p. 127130.

SciELO - Scientific Electronic Library Online. [online]. [citado em: 1998]. [data de acesso: 14/01/2000]. Disponível na URL: Internet: $<$ http://www.scielo.br . 


\section{Gildenir Carolino Santos}

Bibliotecário/Diretor da

Biblioteca Prof. Joel Martins da

Faculdade de Educação da

Universidade Estadual de Campinas e-mail: gilbfe@unicamp.br

Rosemary Passos

Bibliotecário/Supervisora de Seção da

Biblioteca Prof. Joel Martins da

Faculdade de Educação da

Universidade Estadual de Campinas

e-mail: pibrose@unicamp.br 